\title{
Los viajes de intercambio y las ferias. Relatos y vigencia del trueque en la Puna jujeña (Argentina)
}

\section{Exchange journey and fairs. Stories and validity of barter at the Jujuy's Puna (Argentina)}

Liliana Bergesio ${ }^{1}$ https://orcid.org/0000-0003-0273-9434 y

Natividad M. González ${ }^{1,2}$ https://orcid.org/0000-0003-4458-9809

${ }^{1}$ Unidad de Investigación en Comunicación, Cultura y Sociedad, Facultad de Humanidades y Ciencias Sociales, Universidad Nacional de Jujuy, San Salvador de Jujuy, ARGENTINA. Email: lilianabergesio@gmail.com

${ }^{2}$ Centro Interdisciplinario de Investigaciones en Tecnologías y Desarrollo Social para el NOA (CIITeD) - Universidad Nacional de Jujuy - Consejo Nacional de Investigaciones Científicas y Técnicas (CONICET). San Salvador de Jujuy, ARGENTINA.

Email: ngonzalez@fhycs.unju.edu.ar

\section{Resumen}

En el mundo andino son frecuentes las referencias al trueque como sistema de intercambios de bienes y servicios, tanto en relación a procesos históricos como del presente. Sin embargo, no son tan comunes los estudios que se enfoquen en recuperar las prácticas y visiones para el caso de la Puna argentina. Así, este trabajo pretende aportar una mirada amplia sobre el trueque entre productores agroganaderos de la Puna jujeña (extremo noroeste de Argentina, en el límite con Chile y Bolivia) a partir de descripciones etnográficas y entrevistas en profundidad. Esto llevó a identificar que las referencias al trueque tienen dos instancias: una es la histórica, vinculada con los viajes que emprendían los hombres desde la Puna hacia los valles y la otra, actual, se relaciona con las ferias en sus diversas versiones. Y si bien el trueque cuenta con una valoración positiva y una carga cultural e identitaria, es una práctica que parece estar en retroceso y reconfiguración.

Palabras claves: trueque, Puna jujeña, cultura, sociedad, economía.

\begin{abstract}
References to barter at Andean region are frequently described as interchange of goods and services system, related to historical processes as well as present ones. However, studies that focusses on recovering practices and visions for Argentinian Puna are not so common. So, in this text we pretend to contribute with a wide vision about barter among agricultural producers at the Jujuy Puna (northwest extreme of Argentina, at the border with Chile and Bolivia) from ethnographic descriptions and depth interviews. This task entail to identify references to barter that happened to have two instances: an historic one, when men undertake journeys from Puna to valley, and the actual one, that takes place at different kinds of fairs. Although barter is appreciated as a positively cultural element for identity, it's a practice that is being reconfigured and giving ground.
\end{abstract}

Keywords: barter, Jujuy Puna, culture, society, economy.

Recibido: 8 junio 2018. Aceptado: 4 octubre 2019 


\section{Introducción}

A lo largo de la historia distintos pueblos en diversas geografías han intercambiado objetos y servicios sin necesidad de usar el dinero como intermediario. A esta práctica se la denomina genéricamente trueque. Las ciencias sociales no han podido alcanzar una sólida definición de ella, ya que se trata de una práctica atada a situaciones contextuales, por lo tanto sumamente variable, razón por la que su estudio sistemático ha sido un tanto escaso en relación con otros tipos de intercambios. Por el contrario, abundan los estudios de casos que describen situaciones concretas casi en todo el planeta, en los que se analiza esta práctica en el pasado o en el presente, dando cuenta de la variabilidad de este tipo de intercambios, ya que estos se pueden producir entre objetos de especie similar (por ejemplo provenientes de la producción agroganadera), de diferentes ámbitos productivos (como objetos industrializados por otros artesanales) o incluir servicios como parte de la transacción, entre otras combinaciones posibles.

En este trabajo se expone una revisión teórica sobre el trueque, se describen etnográficamente y se analizan experiencias concretas entre productores de la Puna jujeña (provincia de Jujuy, Argentina). Específicamente, en un primer momento, se ha construido un cuerpo de antecedentes y marco teórico sobre la base del relevamiento bibliográfico, tanto de fuentes publicadas como inéditas sobre el trueque e intercambio no monetario en la una jujeña, focalizado en el siglo XX y la actualidad. Luego, se busca describir y analizar casos concretos de trueque, procurando identificar diferentes instancias donde se practica, indagando sobre su vigencia, especificidades y valoraciones.

La estrategia metodológica es de carácter fundamentalmente cualitativa, basada en entrevistas (abiertas y semiestructuradas), observación participante y descripción etnográfica. Esto permitió avanzar en la comprensión de los procesos sociales de construcción de significados involucrados en la relación que se establece entre las representaciones que tienen las y los productores sobre el trueque y los factores sociales, económicos, ambientales y culturales en torno a los cuales se desarrollan sus experiencias vinculadas al trueque, tanto en el pasado reciente como en el presente.

\section{El trueque: principales debates teóricos}

En primer lugar, es necesario dejar de lado cierta subestimación sobre el trueque, fundada en la persistencia del mito nacido en la economía clásica y neoclásica de que se trataría de la versión anterior (en una suerte de línea evolutiva) del intercambio monetario. Desde esta perspectiva, en el trueque yacerían los orígenes del intercambio con dinero y, por lo tanto, del capitalismo moderno; donde el dinero se originaría como una solución a los problemas del trueque. Esta visión se encuentra, asimismo, en aquella idea que indica que el trueque se relaciona de manera directa a los casos de escasez monetaria, opinión recurrente en el sentido común.

Por el contrario, consideramos que estas miradas simplificadoras atentan contra su comprensión y sostenemos que el trueque no es un estadio anterior al intercambio monetario y que no debería definirse por aquello que no es. Si bien se pueden rastrear ejemplos de intercambios por trueque en sociedades históricas, no se trata de "un prototipo arcaico del capitalismo" (Humphrey y Hugh-Jones, 1998, p. 14) ni tampoco es "solamente una institución histórica o peculiar en las economías arcaicas o 'primitivas"' (Humphrey y Hugh-Jones, 1998, p. 11). Por el contrario, es "un fenómeno contemporáneo que cubre tanto transacciones a pequeña o gran escala, y ocurre en y entre muchos diferentes tipos de sociedades" y actores (Humphrey y Hugh-Jones, 1998, p. 11).

Esto lleva a afirmar que tanto históricamente como en el presente, "hay muy pocas, si es que existen, economías que operen sin trueque" (Humphrey y Hugh-Jones, 1998, p. 13), por lo cual se hace necesario enfatizar que el trueque "es un modo de intercambio por su propio derecho" (Humphrey y Hugh-Jones, 1998, p. 14); una forma, entre otras posibles, en que las personas pueden intercambiar sin la intermediación exclusiva y central de la moneda. En este sentido, es necesario enfatizar que si bien a veces el dinero es parte de una relación de trueque, 
no lo es en su aspecto capitalista (como representación de una riqueza) sino como un medio de acceso a otro bien. La presencia de dinero en un intercambio por trueque opera así como representante de un bien y no de un valor, entre otras cosas porque el trueque busca el intercambio de bienes pares y no la acumulación de valor sobre un bien.

No se pretende aquí formular una definición acabada del trueque, lo que, de plano, sería un error. Dado que se trata, ante todo, de una relación y no un tipo de intercambio con características definidas a priori, "el trueque es mejor entendido cuando se lo ve a la luz de su contexto social; en la medida que este contexto varía, lo harán también las características" del mismo (Humphrey y Hugh-Jones, 1998, p. 6). Usualmente los intentos para construir una definición unívoca de trueque implican que se le despoje de su contexto sociocultural. Esto conduce a abstracciones inconsistentes, con reducida correspondencia con los casos concretos que se pueden dar en uno u otro grupo y llevan a la formulación de modelos pretendidamente universales, con nulo valor explicativo, ya que no consideran su diversidad sociocultural e histórica.

El trueque implica una variada gama de acciones sin que necesariamente todas estén presentes en cualquier instancia concreta. Sin embargo, la multiplicidad de registros de trueque en diversos contextos permite diferenciarlo de otras formas de intercambio (monetario y no monetario) e identificar sus principales particularidades. En líneas generales las características que se asocian con el trueque son (siguiendo a Humphrey y Hugh-Jones, 1998):

- El enfoque está en la demanda de cosas particulares, que suelen pertenecer a tipos diferentes; entre otros casos, puede ser de artículos intercambiados por mercancías o servicios.

- Los protagonistas son esencialmente libres y pertenecen a un mismo nivel socioeconómico (paridad); cualquiera puede retirarse del negocio, y al final del mismo, cada una de las partes, permanecer en iguales condiciones que antes de la transacción.
- No hay criterios con los que, desde afuera, se pueda juzgar que los objetos intercambiados tengan un valor similar. Algún tipo de regateo ${ }^{1}$ puede tener lugar, pero no con respecto a alguna medida de valor o numéricamente abstracta, sino que cada uno, simplemente, desea el objeto que el otro posee.

- Si bien en la mayoría de los casos las dos partes de la transacción actúan simultáneamente, también puede darse que ambas estén separadas por el tiempo, cambiando el lugar donde esta se concreta. Sin embargo, el trueque ocurre sobre todo en las situaciones locales cara a cara, en las que la gente y el flujo (procedencia y destino) de los bienes coinciden en un mismo espacio/ tiempo.

- Desde el punto de vista formal, la información (sobre las personas que participan en el trueque y sobre los objetos que se intercambian) es lo esencial para que este tenga lugar (Anderlini y Sabourian, 1998).

Un aspecto relevante a considerar en el trueque es el valor de los objetos intercambiados. En él "desaparece la distinción analítica de simétricos y asimétricos [siendo un] intercambio de bienes por bienes" (Alberti y Mayer, 1974, p. 25). Es, por lo tanto, una forma de intercambio no monetario en la que se requiere que todos los "negocios" se equilibren en un sentido apropiado. En otras palabras, "cada negocio bilateral debe ser tal que, en una proporción dada de intercambio, el valor de lo que cada comerciante vende iguala el valor de lo que compra" o adquiere (Anderlini y Sabourian, 1998, p. 120). El valor no se computa de manera monetaria, sino en un sentido subjetivo. Es por esto que se trata de un intercambio no monetario.

1 Para el caso el ayllu Majasaya Mujlli (Cochabamba, Bolivia) Delgado plantea que "el regateo es parte de la negociación para acceder a precios más bajos o mayor producto intercambiado, pero que sirve fundamentalmente para buscar nuevas alianzas a través de la comprobación de las afinidades, simpatías y complementariedad de energías que permitan un mayor acercamiento que se podría consolidar con el compadrazgo" (Delgado, 2005, p. 254). 
Esencialmente, el intercambio en el trueque está determinado por el interés que cada parte tiene en el objeto del otro, un interés que se satisface por la transacción, donde el valor de los objetos intercambiados es de estricta potestad de quienes intervienen en dicha transacción. Como lo destaca Simmel (1976) desde el punto de vista del individuo y su subjetividad, todo intercambio puede tener discrepancia entre los sacrificios del comprador y los del vendedor, diferencia que normalmente se pasa por alto debido al sinnúmero de convenciones acerca del intercambio que son observadas por ambas partes. Se puede hablar entonces del marco cultural que define la candidatura mercantil de las cosas, ya sea para intercambios monetarios o no monetarios.

Aquí es relevante introducir la noción de "regímenes de valor" que propone Appadurai (1991), que no implica que todo acto de intercambio conlleve una completa comunión cultural de presuposiciones, sino que el grado de coherencia del valor puede variar considerablemente de situación en situación y de mercadería en mercadería (este caso se da, por ejemplo, cuando el intercambio se concreta entre personas de distintas clases sociales y/o grupos étnicos).

De este modo, se puede postular que en el trueque el acto transformador mueve los objetos entre los "regímenes de valor" acordados por los sujetos que participan del mismo, pero no conforma en sí uno nuevo, pues cada situación es en sí irrepetible, más allá del hecho de tener entre ellas alguna que otra similitud. Es decir, en el trueque el valor depende siempre del que cada parte interviniente le otorga a esos objetos en ese momento y contexto específico. Pero, además, en relación a la distinción del valor en el trueque y en el intercambio monetario, es necesario destacar que en el primero los objetos intercambiados tienen para los participantes valores directos de consumo. Por el contrario, en el intercambio de mercado, uno de los objetos intercambiados -el dinero- no tiene uso directo, sino que es meramente un asegurador de otros valores definidos (Simmel, 1976). En el trueque, por otra parte, los actores de la transacción actúan por su cuenta: si ellos deciden que un objeto vale lo mismo que otro, eso es todo lo que importa. Así, en "las relaciones de trueque, las equivalencias entre productos de origen campesino las establecen ellos mismos, por ejemplo una libra de coca es equivalente a una arroba de maíz" (Alberti y Mayer, 1974, p. 27).

En otras palabras, los objetos no son medidos uno con otro por algún criterio externo, sino sustituidos uno por otro mediante un balance interno realizado -únicamente- por los sujetos que intervienen en un intercambio específico. Esto no significa que el trueque implique una ausencia de relaciones sociales, sino todo lo contrario. En este sentido es válida la argumentación de Simmel (1976) cuando sostiene que no es que la sociedad, como una "entidad absoluta", existe y crea intercambio, sino que el intercambio en sí mismo crea los vínculos de la sociedad, lo cual aplica especialmente para el caso del trueque. Es decir, no es que la sociedad posibilite las relaciones de cohesión, la división del trabajo o cualquier otra institución que pudiera desarrollarse en su interior, sino que es ella misma la síntesis general de estas relaciones. Por su parte, el trueque es, en este sentido, una forma de intercambio "que crea relaciones sociales a su manera" (Humphrey y Hugh-Jones, 1998, p. 15).

\section{El trueque en la región andina}

Numerosos trabajos describen la importancia y diversidad de intercambios en el área andina. Su profunda antigüedad ha sido documentada por investigaciones arqueológicas que dan cuenta de intercambios de productos entre áreas realmente alejadas, tanto en sentido longitudinal a la cordillera, como los registrados entre Tiwanaku (sur del lago Titicaca) y San Pedro de Atacama (en el Período Medio, entre 500-1000 dC), como otros en sentido transversal a través de circuitos que conectaban el oasis de Atacama con la región central y norte de la Puna jujeña y el río Loa con Nor Lípez (con registros, incluso, desde el Período Temprano) (Núñez y Nielsen, 2011).

Ya en épocas coloniales, desde una perspectiva etnohistórica, Burchard (1974) traza una línea de continuidad de este tipo de intercambios en comunidades del departamento de Huánuco, en Perú. Este autor recupera relatos del visitador español Ińigo Ortiz de Zúńiga, quien daba cuenta de ellos para 
el año 1562, afirmando que la importancia de estos intercambios radicaba en su capacidad de facilitar lazos de alianza e interdependencia entre diversos grupos étnicos mediante el canje de preciados recursos, enfatizando que "estos intercambios se basan más en la necesidad que en un interés comercial" (Burchard, 1974, p. 216). Y llega a la conclusión de que "en contextos del sistema socioeconómico andino 'tradicional', los intercambios [...] entre grupos étnicos diferentes en zonas ecológicas distintas, eran una modalidad importante en el proceso de la 'verticalidad' ecológica” (Burchard, 1974, p. 217). Estos ejemplos (históricos y arqueológicos) dan cuenta de la profunda raíz temporal de este tipo de intercambios en la región. Además, se plantea una cuestión que es de suma importancia, ya que caracteriza al trueque como un tipo de relación que se activa y actualiza en cada oportunidad, y no una institución (algo ya definido de una vez).

En lo referente a la complementariedad económicoproductiva, cabe recordar que el factor ecológico tuvo gran importancia en el desarrollo de los distintos grupos étnicos andinos, antes y después de la colonización europea y, al menos en parte, aún la tiene en el presente, ya que el manejo, la administración y planificación del territorio se originan articulando los distintos ecosistemas y zonas productivas, en un tipo de integración con eje en la verticalidad del espacio. $^{2}$

El control o acceso a una máxima cantidad o variabilidad de pisos ecológicos (o ambientes) fue un ideal compartido por distintos grupos étnicos, por lo que en este marco de integración y complementariedad los principales recursos económicos eran otros seres humanos ligados por lazos de parentesco y reciprocidad. En este ideal, las papas y las llamas, es decir el chuńo y el charqui (papas y carne de llama deshidratadas), estaban unidas ya que no solo eran los elementos básicos de la alimentación, sino también de una economía de distintas altitudes, pues el objetivo era tener acceso, de una manera u otra,

2 En este trabajo no se entrará en el debate de las múltiples clasificaciones de las zonas ecológicas que se distinguen a lo largo del área andina tanto por parte de diversos autores como por las tipologías étnicas, por exceder los límites del mismo. Para una revisión de esto véase Schulte (1996). tanto a zonas de cultivo como de pastura (Murra, 1975). Jugaban un rol central en la posibilidad de lograrlo, en el caso de los Andes, los sistemas de intercambio basados en el trueque. ${ }^{3}$

Más cerca del presente, la mayoría de los intercambios por trueque parecieran seguir una lógica similar y no realizarse con "fines de lucro, característicos de las relaciones comerciales, sino más bien para fines de auto abastecimiento" (Alberti y Mayer, 1974, p. 27). Debido a que las unidades domésticas ${ }^{4}$ campesinas se encuentran articuladas o insertas parcialmente en el sistema capitalista mayor, el trueque posibilitaría el acceso a bienes o servicios necesarios, ya sea sin la incorporación de esta transacción dentro de los términos comerciales o para obtener productos que no se suelen encontrar a la venta. En relación a lo primero, el cambio de carne por papas evitaría un circuito que incluyera la venta de la carne y de las papas y la posterior compra del otro producto, que ya habría cambiado de valor al ser incorporado al sistema capitalista (Palerm, 2008). También se han documentado casos en los cuales en el intercambio entre miembros del ayllu Laymi (norte de Potosí, al sur de Bolivia), aunque de distintas parcialidades, obtienen mayor cantidad de productos en comparación a un intercambio con un foráneo (Harris, 1987).

Sin embargo, aunque en menor número, también hay ejemplos que resaltan la relación entre el trueque y otros tipos de intercambios, en los que se observa que el autoabastecimiento no es el fin último. Así, Custred (1974), para la sierra peruana, muestra que existe la posibilidad de que las tasas e intercambio del sistema de trueque y las que se establecen en el sector de mercado o monetario (denominado "nacional" por Custred) discrepen entre sí, lo que

3 Las particularidades del trueque en el área de estudio, tanto de casos históricos como actuales, será atendida en un apartado posterior.

4 El concepto de unidad doméstica es más amplio que el de familia, ya que no solo incluye a sus miembros sino que se extiende a vecinos, paisanos, amigos y compadres, quienes pueden residir en un mismo lugar, o no, conformando una extensa red que considera a miembros intra y extrafamiliares en la cual prevalece un sistema de contraprestaciones materiales y simbólicas que permiten en conjunto la reproducción de la vida (Bergesio, 2004). 
es aprovechado en este caso por los pastores de llamas para obtener el mayor beneficio en dichos intercambios; esto porque las largas expediciones de los llameros del altiplano peruano son, en efecto, una combinación de transacciones de trueque y de mercado en una compleja cadena de intercambios que, a la larga, beneficia al campesino que trata de autoabastecerse. Mientras que Orlove (1974), a partir de un estudio realizado en la provincia de Espinar (al sur del departamento del Cusco, en el límite de dos zonas productivas, una más baja, donde se hace agricultura, y otra más alta con ganadería de trashumancia), demuestra que la misma combinación de transacciones de trueque y de mercado puede ser utilizada por intermediarios y campesinos, ya no para el autoabastecimiento sino con fines de lucro de tipo empresarial, y que productos de exportación como la lana empiezan su trayectoria hacia el sector nacional e internacional mediante cadenas de transacciones que, en sus primeras etapas, frecuentemente son llevadas a cabo mediante relaciones de trueque. Estos trabajos, más allá de su antigüedad, logran dar cuenta de prácticas combinadas de intercambio por trueque e intercambio de mercado, donde el primero persigue diferentes fines en distintos contextos en la segunda mitad del siglo XX. ${ }^{5}$

Estos registros reafirman la idea y la necesidad de ver el trueque como inseparable de otros tipos de intercambio -de regalos, crédito, comercio formalizado, de mercancías sin moneda, reciprocidad, etc.- dado que no siempre hay límites firmes y seguros entre ellos: el trueque, en una u otra de sus variadas formas, coexiste con estas modalidades de intercambio, a menudo se une en secuencia con ellas y comparte algunas de sus características (Humphrey y HughJones, 1998). En algunos casos, también las partes implicadas pueden ver la misma transacción desde diferentes perspectivas: una como trueque a secas, en su sentido más puro; otra, como una forma enmascarada o sustituta de intercambios monetarios en los que en realidad se intercambian objetos pero pensando en el valor monetario de los mismos (Hugh-Jones, 1998). "Esta es una razón más para no aislar el trueque como una clase limitada y darle una

5 Sería relevante conocer si continúan en el presente, pero la ausencia de trabajos en relación a este tema no permite actualizar esta información. definición esquemática e inequívoca" (Humphrey y Hugh-Jones, 1998, p. 6), advirtiendo sobre la necesidad de no analizarlo como un fenómeno aislado sino contextualizado.

Para el caso de los Andes bolivianos, se plantea que el trueque se realiza de "acuerdo a las necesidades determinadas por el ciclo de vida familiar" (Delgado y Delgado, 2014, p. 57) destacando que "al momento del trueque no existe el concepto monetario o fiduciario de la economía occidental, sino que se establecen otras medidas típicas de la cosmovisión andina" (Delgado y Delgado, 2014, p. 58, énfasis nuestro). Aquí se resalta la importancia que tiene este tipo de intercambio dentro un marco general de entendimiento, ya que al dejarse de lado la búsqueda de lucro -que inevitablemente pone las necesidades propias por sobre las del otro sujeto que intercambia-, la satisfacción compartida resulta ser una característica intrínseca de la modalidad.

Tapia Ponce (2006) plantea lo mismo para el departamento de Cochabamba cuando afirma que en la actualidad se tiene acceso a la producción de otros pisos ecológicos, no solo mediante estrategias familiares sino de algunas otras, como los frecuentes viajes que realizan los productores hacia esa área con propósitos de intercambio y trueque de productos. "La mayor parte de los comuneros realizan estos viajes, lo hacen en forma temporal con el fin de obtener en otros espacios socioeconómicos productos complementarios para el consumo familiar, a través de relaciones reciprocas de intercambio de productos como es el trueque" (Tapia Ponce, 2006, p. 167, énfasis nuestro). Sostiene que esta estrategia basada en los viajes para intercambiar productos mediante el trueque "es muy importante para diversificar los productos en la alimentación familiar" (Tapia Ponce, 2006), aunque también se trata de la mantención de redes y espacios de acceso a esos recursos como un fin en sí mismo.

Para el caso de la puna de Atacama, que se extiende entre las provincias argentinas de Salta y Catamarca y el vecino Chile, también hay registros de estos viajes de intercambio, con similares características, en los que prima el trueque. Este depende fuertemente de las relaciones personales -amigos, parientes, conocidos-, lo cual le ańade un "valor agregado" que 
permite enriquecer la caracterización social y cultural de la región. De esta forma, el estudio de las relaciones parentales, de amistad y comerciales, y sus redes a través de las unidades familiares y en los viajes, aporta valiosa información para la descripción y análisis de la estructura social de un ámbito bastante extenso del altiplano andino (García, Rolandi, López y Valeri, 2002). Puntualmente, en las áreas rurales de Catamarca (noroeste de Argentina) los productores han combinado la economía de mercado con el trueque desde hace mucho tiempo y está asentada sobre la construcción de vínculos sociales (García, Rolandi y Valeri, 2003).

Otro estudio que se enfoca en la puna atacameńa (Salta, noroeste de Argentina) resalta la importancia que tiene la articulación territorial que realizan los pastores a través de la movilidad, no solo en términos de lugares específicos de pastoreo, sino también en espacios amplios de aprovisionamiento (Abeledo, 2014). En efecto, a través de los intercambios (entre ellos el trueque) poblaciones dedicadas a la ganadería de altura acceden a recursos de otros espacios, concentrados en una población, un compadre, una feria, que de otro modo se encuentran dispersos. Esta "bisagra" también cumple su función en el sentido inverso, pues a la Quebrada de Humahuaca (área central de Jujuy, extremo noroeste de Argentina) durante la década del noventa todavía llegaban semillas de papas de Bolivia -a través del intercambio con otros productos- que eran distribuidas entre los agricultores de la zona. ${ }^{6}$

\section{El trueque en la Puna jujeña}

Las características ecológicas de los Andes, tal como se indicó, determinan la relación entre los habitantes de distintos ambientes productivos. Esta relación se ha establecido de diversas maneras (desde el control directo de diferentes espacios hasta el intercambio comercial entre productores, como extremos de un continuum). En el caso específico de la Puna jujeña (departamentos de Susques, Cochinoca, Rinconada, Santa Catalina y Yavi en la provincia de Jujuy, extremo noroeste de Argentina, limitando con Chile al este y Bolivia al norte), sus pobladores practican de forma mayoritaria la ganadería de

6 Javier Rodríguez, com. pers., noviembre de 2018. altura de llamas y ovejas (González, 2016), la cual implica un tipo de relación especial con el espacio (Göbel, 2002). ${ }^{7}$ Por ello, esta área pastoril se complementó económicamente a lo largo de la historia (colonial y prehispánica) con las áreas agrícolas por medio de intercambios que tuvieron diferentes formas, en las que prevalecieron los viajes en caravanas (Göbel, 1998). Debido a que los habitantes de los valles -donde se practica predominantemente la agricultura-, también necesitaban productos de las zonas altas y ganaderas, estos viajes para proveerse de "lo otro" son una práctica antiquísima (Cipoletti, 1984; Bugallo, 2008).

Así, en la Puna jujeña el trueque a gran escala aparece asociado, desde períodos prehispánicos hasta mediados del siglo XX, a las grandes caravanas de llamas (y luego de burros y mulas) que iban hasta San Pedro de Atacama (Chile), Potosí (Bolivia) y dentro de la provincia a la Quebrada de Humahuaca y a la vecina provincia de Salta, al este. Esta estrategia perseguía el mismo fin ya descripto: la diversificación de productos alimentarios (Cipolletti, 1984). En estos casos el trueque estaba regido por la reciprocidad equilibrada, es decir, la existencia de un intercambio simultáneo e inmediato de bienes tradicionalmente tipificados como equiparables (no de cualquier clase

7 En la Puna jujeńa, en general, todos los terrenos de pastaje tienen dueño, ya sea registrado oficialmente o de uso consuetudinario; cuando se conforma una nueva pareja, la definición sobre qué lugar usaran para pastear sus rebaños es una cuestión que se dirime al interior de la familia ampliada. Por otra parte, cuando una estancia queda deshabitada, es decir, sin nadie que continúe usufructuando del terreno alrededor, es esperable que algún vecino la utilice hasta que la situación se regularice (p.e., cuando una persona anciana no puede continuar con las tareas del campo y no tiene quien la sustituya -sobre todo por la migración de los jóvenes hacia las ciudades $\mathrm{u}$ otros destinos por motivos laborales- o fallece, se espera que en algún momento sus parientes cercanos se presenten con los vecinos y se disponga una compraventa, cuidado "al partir" u otra alternativa). En los casos en que no estén legalmente regularizados los títulos de propiedad (pues son tierras fiscales delimitadas por medio de mojones y algún alambrado), la posesión familiar y los derechos sobre la tierra se reconocen y existen los mecanismos para regularizar su transferencia (a terceros o entre los descendientes), ya sea mediante la compra de terrenos a hermanos/as o tíos/as (Tomasi, 2013; González, 2016). 


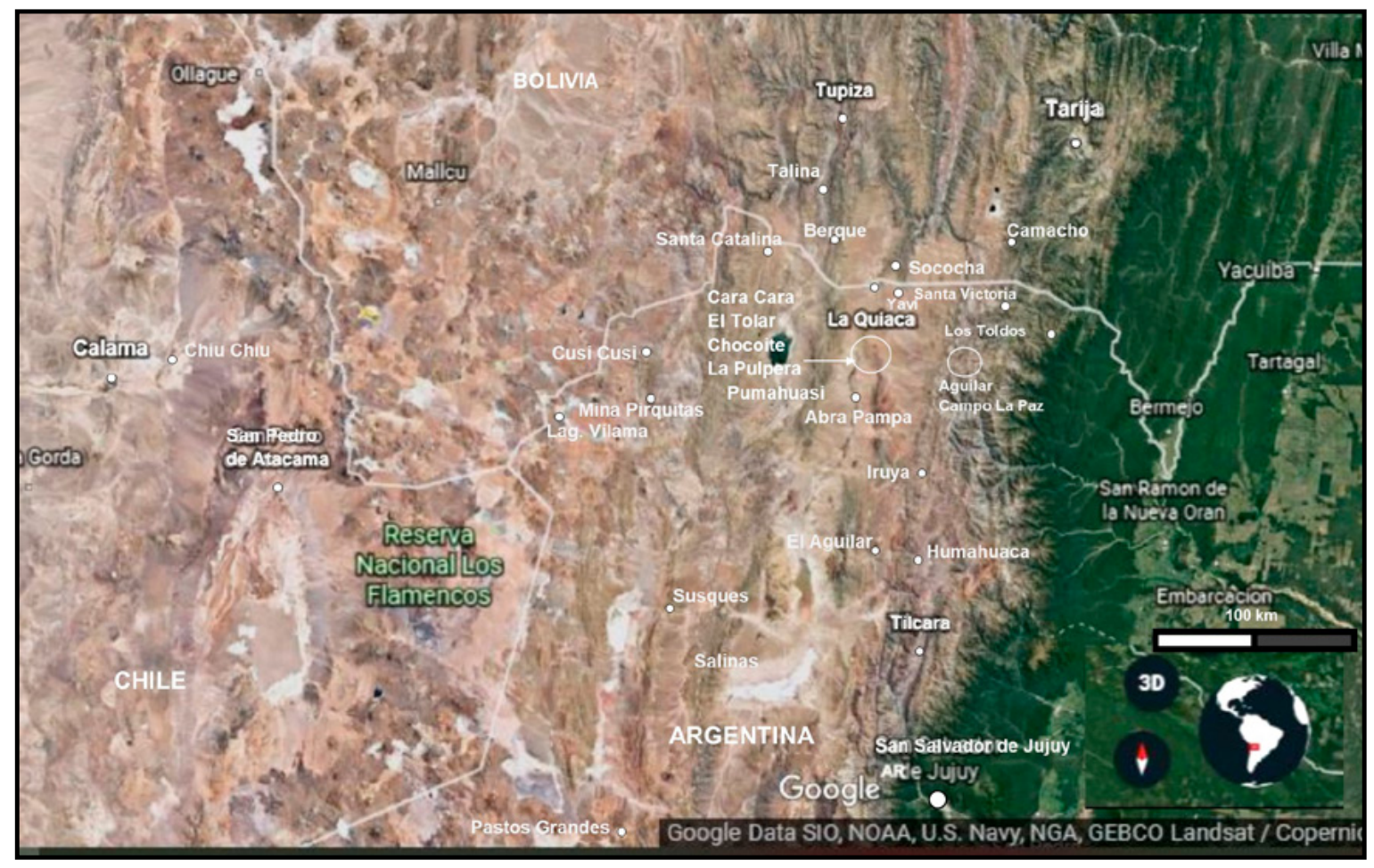

Figura 1. Ubicación de las localidades mencionadas en el texto (se excluyen las citadas en bibliografía).

Fuente: Elaboración propia basada en Google Earth.

de bienes), de acuerdo con equivalencias relativamente estables. La obligación del reintegro por el valor recibido era manifiesta, y en caso de emplearse dinero este -cualquiera fuere su forma- solo era utilizado como patrón (Madrazo, 1981). Con posterioridad, el trueque aparece asociado a las ferias, aunque no todos los productos son pasibles de trueque directo, ya que hay algunos para los cuales no existen tasas de cambio fijas, en cuyo caso el intercambio pasa por alguno de los productos con mayor posibilidad de permuta (como carnes, sal, papas) o por dinero. Las tasas de cambio vigentes en las ferias expresan una relación cuantitativa entre bienes de distintos tipos: la cantidad juzgada adecuada culturalmente de cada término del intercambio para que pueda concretarse la operación del trueque. Esta adecuación no se traduce necesariamente en igualdad en el cambio de trabajo social, pero tampoco es un arreglo arbitrario, aunque su lógica sea difícil de desentrañar (Karasik, 1984).

Durante "las primeras décadas del siglo XX los viajes de intercambio como la participación en ferias constituían ejes de la economía campesina puneña" (Bugallo, 2008, p. 10). Sin embargo, estas formas de circulación "antes de promediar el siglo [XX] se transformaron casi completamente y sólo se mantuvieron en parte bajo la forma de un fenómeno residual o conservaron su carácter como algo subyacente a las nuevas modalidades" (Madrazo, 1981, p. 219) de intercambio. Los factores que provocaron la interrupción de los viajes de intercambio fueron variados, pero este tema será tratado más adelante con mayor profundidad.

Así, los viajes a Chile, a la región de San Pedro de Atacama, fueron perdiendo intensidad con el trazado de la frontera a fines del siglo XIX, aunque persisten y son descriptos por Rabey, Merlino y González (1986) para el año 1984 y Göbel (1998 y 2009) para fines del siglo XX. En este caso el resguardo policial intentó controlar las actividades de movilidad, intercambio y relaciones sociales entre la Puna jujeńa y el desierto de Atacama y los valles circumpuneños, que se realizaban de modo consuetudinario y con anterioridad a la implantación de 
las fronteras nacionales (González, 2016). Desde la perspectiva policial y de los Estados nacionales, la vigilancia de la frontera atacameña se realizó para reprimir las actividades consideradas ilegales y proscritas, argumento suficiente para perseguir a viajeros, arrieros y comerciantes transcordilleranos. Estos eran acusados de "ingreso ilegal", "contrabando", "violación de normas sanitarias" y "caza furtiva", pero aun así, Molina Otarola (2013) sostiene que en fechas recientes las relaciones tradicionales transcordilleranas no se habían extinguido, aunque sí están debilitadas. De esta manera, los viajes realizados por familias del área puneña y el desierto de Atacama transportando sus propios animales y bienes para el intercambio articularon en ambos sentidos el territorio transfronterizo argentino-chileno, actividad sustentada en las relaciones sociales a distancia que se desarrollaron evitando los controles de los Estados nacionales. Esta arriería se caracteriza por el intercambio y el trueque, a cuyo propósito las personas elaboraron sus propios viajes y diseñaron particulares estrategias de intercambio, sustentadas en redes sociales (Molina Otarola, 2011).

Algo similar pasó con Bolivia, donde el circuito llegaba hasta Tupiza, Talina e incluso la feria de Huari en Oruro, pero esta ruta se interrumpió debido a la Guerra del Chaco entre 1932 y 1935 (Göbel, 1998) y los controles fronterizos, que también los fueron haciendo estos viajes menos frecuentes. Dentro del territorio argentino resultaron cada vez menos eficientes; algunos factores decisivos fueron el desarrollo minero que se inicia en la década del treinta y la estabilidad de ingresos monetarios (González, 2016), aspectos sobre los cuales volveremos más adelante.

En la actualidad los procesos de complementariedad económico-productiva siguen siendo parte de la economía doméstica, aunque en algunos casos de manera más importante que en otros. En este sentido, las ferias periódicas (como las de Pascua en Abra Pampa y Yavi o la Manka Fiesta en La Quiaca) siguen siendo muy convocantes en términos económicos pero también socioculturales (Bergesio, 2007; Bugallo, 2008; Bergesio, González y Golovanevsky, 2016).

Es en este marco que el trueque se presenta como una forma de intercambio posible, resultado de un largo proceso que devela múltiples aristas. Al respecto, algunas de las apreciaciones que tienen del trueque las y los puneños a quienes se entrevistó pueden dar una idea de la complejidad del asunto, ya que este tema toca la alimentación, patrones de consumo, la valorización de la identidad cultural y la integración a la sociedad mayor y al sistema capitalista. Resaltamos que la visión preponderante es que el trueque corresponde al intercambio de productos, por lo que se limitan algunas posibilidades de realizarlos por servicios o como crédito. Según los relatos de actuales productores de la Puna jujeña (de diferentes localidades y parajes de los departamentos de Cochinoca y Santa Catalina), en el presente no hay tasas fijas de cambio, como sí las había en el pasado; la dieta alimentaria no es tan variada y se basa en productos industrializados, lo cual dificulta el trueque. Pero, en contraste, este es visto como parte de la identidad y de cierta forma de resistencia al capitalismo (que impone valores y tasas ajenos) y una manera de fortalecer a la comunidad.

Antes habia acuerdo en el valor de las cosas. Se sabía lo que valía y el cambio era justo $y$ nadie quedaba desconforme. Ahora eso no es asi, si uno quiere cambiar y no conoce al otro no sabe la calidad y ya se hace difícil el cambio. Ya no es como antes [...] También cambió la alimentación, ahora todo es harina, fideos $y$ arroz (Ramón, de Cara Cara, agosto 2016, énfasis nuestro).

El trueque tiene que ver con la identidad, ahora todo es pura plata y el capitalismo está matando a lo que la comunidad de verdad hace. Ahora todo depende de la plata y todos quieren plata y eso no es bueno, no nos ayuda [...] Ahora uno quiere lo del otro. Quiere la ropa de la ciudad. Y eso es plata. Y ya es como que con lo que hay acá, con lo que se produce, no alcanza. Todos quieren plata (Norma, de El Tolar, agosto 2016, énfasis nuestro).

Es importante recuperar el trueque porque con eso que se produce alcanza para comer bien, para todo, no hace falta más. Por eso hay que recuperarlo [...] Hay que ver de volver al trueque, es bueno que quieran volver al trueque porque 
asi se puede tener lo que se necesita (Clemente, de Cusi Cusi, agosto 2016, nuestro énfasis).

En la Puna jujeña hemos de encontrar dos modalidades de importancia: por un lado se encuentran los antiguos viajes que emprendían arrieros puneños (con llamas o burros) hacia zonas más bajas y por el otro, las ferias periódicas. En relación a los primeros, si bien en la actualidad ya no se realizan, sí son parte importante de la historia de vida de pobladores de mayor edad, constituyendo un elemento de la identidad puneña. Por el contrario, las ferias han tomado diversidad de formas en los últimos ańos, por lo que se registran algunas antiguas y otras más recientes.

\section{A. Viajes de intercambio: trueque entre conocidos a tasas estables}

Entre los meses de mayo y agosto muchos hombres adultos, ocasionalmente acompańados por adolescentes o niños que oficiaban de aprendices, solían emprender viajes (hacia localidades en otras zonas ecológicas) en busca de los productos necesarios para complementar la economía de sus hogares; estos se han documentado de manera persistente en Jujuy hasta la década del ochenta y en Bolivia hasta la del noventa. Sin embargo, aunque de forma menos frecuente, en Pastos Grandes (puna atacameña en Salta, norte de Argentina) algunas familias "aún incorporan entre sus estrategias de diversificación económica la tradicional práctica de viajar a los valles" (Abeledo, 2014, p. 36), y también entre 2013 y 2016 en Santa Catalina (extremo norte de Jujuy) se registró el arribo de caravanas de llamas provenientes de Colcha K en Nor Lípez, Bolivia (Vilá, 2018). Pero, definitivamente, los viajes ya no son tan frecuentes y generalizados como lo fueron en el pasado.

Estos viajes se concentraban en el otoño, cuando los productos agrícolas ya estaban maduros y los animales que debían emprender la travesía se habían alimentado con buenas pasturas durante el verano; además era un buen momento para carnear los que serían destinados al intercambio (Cipoletti, 1984). En la actualidad los largos viajes caminando se han reemplazado por otros que se emprenden con los mismos fines, pero en camiones o colectivos, por lo que pueden realizarse varias veces al ańo, con el consecuente cambio en la estructuración general del calendario y el ciclo de aprovisionamiento.

El principal objetivo económico, tanto de los antiguos viajes de caravanas como de los actuales con otras formas de movilidad, es la obtención (mediante trueque o compra) de los productos necesarios para complementar la producción ganadera y las necesidades domésticas en general (puesto que también se adquieren productos de almacén, ropa y otros bienes industrializados -incluso materiales de construcción). Cabe indicar que la otra fuente de acceso a estos bienes era a través de los viajantes (vendedores en camión) que recorrían los pueblos y parajes vendiendo diversas mercaderías y comprando otras, generalmente fibra o hilados de llama u oveja; estos productos solían tener un aumento considerable de su precio respecto de las ciudades donde se abastecían.

En los antiguos viajes el trueque se realizaba a tasas fijas, pero estas podían variar según las localidades (lo que brindaba a los arrieros la posibilidad de acceder a más productos yendo más lejos), en general sin intermediación monetaria (en todo caso el dinero podía ser empleado como medio de conversión entre cantidades de productos que no solían tener una tasa prefijada) (Madrazo, 1981; Cipolletti, 1984; Karasik, 1984; Rabey et al., 1986). En relación a las tasas, Olivia Harris indica que en los intercambios entre productores se prefieren las medidas de volumen a las de peso, estando las últimas relacionadas con intercambios "para el beneficio y no para consumo directo" (Harris, 1987, p. 19).

Estos viajes de caravanas estaban basados en una importante y estable relación entre ganaderos y agricultores de zonas más bajas. Cada arriero sabía a qué pueblo ir y con quién realizaría el cambalache o trueque; estas personas se denominaban caseros, colegas u otra forma similar; también era común que entre ambos fueran compadres, ${ }^{8}$ participando de la red de parentesco ampliada. Estas relaciones eran asimismo fundamentales para la circulación de información

8 Es decir, que alguno de los dos apadrinara a algún miembro de la familia del otro. Es un vínculo político de mucha importancia y estabilidad en los Andes. 
(sobre todo de tipo productivo, por ejemplo informando dónde habían buenas cosechas o dónde había caído helada y no había cultivos, en qué lugar se cambiaba mejor tal o cual producto, etc.).

El proceso comenzaba con la preparación de los productos a intercambiar, los que variaban según el destino. En las travesías hacia los valles bolivianos de Tupiza, Sococha o Tarija, desde la Puna jujeña se llevaba principalmente carne, tanto fresca (en cuartos) como seca (charqui y/o chalona); ${ }^{9}$ grasa $y$ sal (en panes), que ocupaba un lugar importante en la lista de productos puneńos, recolectada en los salares próximos o comprada a vendedores ambulantes.

Los principales destinos de los viajeros se relacionan con los lugares relativamente cercanos pero ambientalmente diferentes, lo que les permitía acceder a productos de otras ecozonas. Así, del área de Cusi Cusi se viajaba hacia San Pedro de Atacama (u otros sitios cercanos, en el valle del río Loa, como Calama o Chiu Chiu), los valles bolivianos de Sococha, Tupiza, Talina o Tarija (y sus diversas localidades). En cambio desde otras zonas de la Puna jujeña los viajes podían realizarse hacia la Quebrada de $\mathrm{Hu}$ mahuaca, el propio valle de San Salvador de Jujuy o los valles salteños de altura como Santa Victoria, Iruya, Los Toldos y alrededores. Además, los centros mineros de Pirquitas y El Aguilar constituían un destino compartido entre diversos poblados, ya que hasta mediados de los años ochenta contaban con una importante concentración de población.

En relación a las rutas seguidas por los arrieros, se ha registrado una cierta especialización en los destinos (Cipoletti, 1984), seguramente por el conocimiento necesario de los caminos y sus derroteros; además de que estas rutas se seguían por tradición familiar o "heredadas" (Nielsen, 1997-1998). También se evaluaban cuestiones ligadas al rendimiento del viaje en relación al momento del ańo, las diferentes tasas de intercambio, noticias sobre las cosechas, etcétera. El conocer el lugar (y a las personas allí) determinaba la

9 Trozos de carne desecados al sol -el primero sin huesos, el segundo con ellos-. Como en otros casos, las definiciones pueden cambiar, por lo que estos términos también pueden referirse a distintos tipos de carnes (caprinos, ovinos, camélidos y vacunos). elección del destino del viaje (Nielsen, 1997-1998; González, 2016), ya que un buen trueque se produciría con los compadres o colegas, y por lo tanto podría realizarse una estimación de la cantidad de productos que se obtendrían del viaje. Al respecto, en situación de entrevista se pudo verificar que las tasas estables se mantenían con estas personas, los colegas o compadres y que en los casos en que el cambalache debiera realizarse con otros (ya sea del mismo lugar o de otro destino), este se efectuaba "peso a peso" (aunque esto pudiera ser en realidad "volumen a volumen”), como un modo de equiparar productos. Aunque "el cambio por peso no era beneficioso para los ganaderos" (don Cristóbal de Chocoite).

Los viajes de intercambio tal como se llevaban a cabo antańo, con tropas de llamas o burros, caminando durante semanas por senderos desiertos $y$ deshabitados, han declinado. Son numerosos los factores que llevaron a esta situación, entre ellos se debe mencionar la creciente motorización que da preeminencia a la integración horizontal en detrimento de la vertical (Schulte, 1996; Quiroga Mendiola, 2014) y las normas de tráfico estatal que, por ejemplo, restringen la comercialización de ciertos productos o no permiten el tránsito con animales en las ciudades (Rabey et al., 1986). Además, es necesario indicar que no fue un proceso que se dio de manera uniforme sino que estuvo ligado, en cada familia, a cuestiones como el trabajo asalariado de los hombres (p.e., en las grandes mineras presentes desde 1930) y otros factores (Madrazo, 1981), como fueron los viajes a los ingenios azucareros, la migración hacia centros urbanos (ocurrida de manera importante hacia la década del setenta), el mayor acceso a bienes foráneos (situación que se produjo de manera heterogénea en la región, ya que los lugares cercanos a la vía del ferrocarril -hoy la Ruta Nacional 9- sintieron ese impacto antes que otros más alejados). Y finalmente, un doble proceso que parece haber acrecentado esta tendencia es el ingreso de la llama al mercado, tanto por su carne como por la fibra (si bien ambos productos ya eran comercializados, en la década del noventa surgieron como productos de nichos distinguidos, tanto en el "gourmet" como en el de la indumentaria fina o con alto valor agregado), por lo que el objetivo de su crianza cambió (Nielsen, 1996; González, 2014). 
Así, se han incrementado las posibilidades de acceder al dinero (incluso con mayores oportunidades de empleos con relativa estabilidad o el acceso a planes sociales y subsidios) y a los bienes necesarios sin tener que realizar estos viajes. Por otra parte, los agricultores también han vivido estos cambios, y con el tiempo "habían perdido el interés en hacer trueque con los pastores" (Abeledo, 2014, p. 49), de modo que, aunque viajaran, el trueque no se llevaba a cabo o se realizaba con tasas o por productos de menor interés para los ganaderos. A raíz de estas transformaciones, los circuitos del intercambio se modificaron, así como también las posibilidades de acceso a bienes foráneos o extrarregionales, con la consecuente disminución de productos ligados a los antiguos patrones de consumo, como la harina de maíz (Bugallo, 2008). El sacrificio que estos viajes implicaban para los arrieros dejó de tener su compensación.

En este sentido se pueden recuperar, sintéticamente, los relatos de dos productores puneños, Leonardo Flores de Cusi Cusi y Cristóbal Martiarena de Chocoite. $^{10}$

El relato de don Leonardo da cuenta de un esquema amplio de intercambios basados en los viajes, que no solo incluía los requerimientos anuales de su familia (esposa e hijos), sino que además debía prever todo un circuito de intercambios que realizaría en diferentes localidades. Según cuenta, desde Vilama (en Jujuy) viajaba a San Pedro y Calama en Chile, a Berque y Sococha en Bolivia y a Mina Pirquitas y Salinas en la propia Puna jujeña.

- ¿Y después adónde iba?

Esa carne la vendía en Pirquitas [ahí] compraban mucho. Le vendia, ganaba platita, con esa platita yo iba a Camacho, Tarija. De ahi traía harina, harina de maiz, trigo, lo que se precisa. Asi he sufrido. Aqui he viajado... yo he viajado como treinta vueltas más fácilmente, toditos los años [...] Después, será como 20 o 30 años que no he ido a Camacho. Después he ido, del

10 La entrevista a don Leonardo Flores se realizó en Cusi Cusi, en septiembre de 2012, en tanto que don Cristóbal Martiarena fue contactado en San Salvador de Jujuy, en septiembre de 2016.
Camacho, he ido a Talina, es más para acá, Vilte [Berque], por ahi andaba. Después he ido Quebrada de Sococha, después ya me encontrado con buenos negocios en Yavi. Ahora voy Yavi, pero no con tropa.

- ¿En colectivo?

Ah... en colectivo, de aqui voy en colectivo a $L a$ Quiaca, de La Quiaca tengo hijos y me llevan [en] algo móvil.

-¿Qué lleva a Yavi?

Se lleva... sogas, chales.

- ¿En la feria de Pascuas?

En Yavi, sí. Pero ahora hay feria allá, en el Yavi chico, no sé cuánto me han dicho, jen julio!

He ido, todos los años voy. iPor eso tengo maiz!

Este último comentario de don Leonardo indica cómo se van combinando las posibilidades con las necesidades. El maíz es una necesidad permanente para él y lo adquiere mediante nuevas vías. En su caso, el trueque permanece ligado a su necesidad de maíz (aunque no sucede así en todas las familias puneñas, ya que muchas han cambiado su alimentación, preponderando el arroz y los fideos).

Don Cristóbal vive en el campo, cerca de Pumahuasi (departamento Yavi, Jujuy). Cuenta que, cuando era niño, solía acompañar a su padre hasta el departamento de Santa Victoria en Salta (valles), a un pueblo llamado Aguilar (anteriormente denominado La Coya) u otros lugares, como Campo La Paz. ${ }^{11}$ Eran caminatas de varios días que ellos realizaban con burros.

Yo era chico... tenía 11 años. Yo empecé a trabajar con el finado mi viejo a los 10 ańos, a los 8 ańos ya viajaba con mula, recorría, a ver, hacíamos $20 \mathrm{~km}$. Viajábamos 10, 15, 20 días, ¡un mes!"

Como en los otros casos, preferentemente partían entre mayo y julio, para lo cual con anterioridad debían realizar un viaje a las salinas a buscar la sal, que luego llevarían al valle. Llevaban carne (fresca y charqui) y sal, para volver con maíz (mazorca o

11 No fue posible identificar la localización exacta de estos lugares, sin embargo suponemos que se ubican en los valles de altura entre la Puna jujeña y el norte salteńo. 
harina), papas, ocas y habas. Estos alimentos constituían, en su conjunto, las provisiones para el año entero, por lo que eran viajes de gran importancia. Don Cristóbal no dio detalles sobre si su padre tenía algún tipo de empleo, en cambio sí resalta que la escuela era relegada ante la necesidad de los viajes.

De Aguilar sacábamos papa, haba, oca. Todo eso. Todo eso era para un presupuesto, para más adelante, para ya tener la mercadería para un año. Eso era en mes de mayo. Como en esos años no habia tanta asistencia a la escuela, mi viejo me decía: "Bueno hijito, a preparar los caballos". Teniamos 30, 40 burros. Primero ibamos a salinas, mi viejo iba con otro amigo $y$ ahi estaban como 15 dias trayendo sal y en esos 15 dias traíamos la carga para los burritos. Después ya empezábamos a cantear la sal, todo parejito, para viajar al valle. En el valle se cambalacheaba con maiz, con la papa, se hacia moler la harina, con esa harina de maiz, de habas, jte duraba un año! Con costales grandes [...] Y el cambalache era eso. La sal, después llevábamos coca, alcohol, charqui, la carne fresca. Eso eran los cambalaches que haciamos. - ¿Y traían las papas...?

Todo eso... para las harinas. El maiz, las habas, también se hace moler. Entonces era un repuesto ya para toda la comida.

Los cambios se realizaban, en general, con gente con la que ya tenían relación; con ellos trocaban según tasas fijas.

Mi viejo ya tenía. Era como... ya tenía presupuesto para cambiar, ya le esperaban. El otro ya esperaba... mi viejo sabia que ya tenía que llevar y le esperaban con maiz... con todo. Ya llegaban y descargaban y le daba el maiz.

-¿De años ya se hacía?

De años... sí.

- ¿De la cantidad que ustedes llevaban de carne y otras cosas, ya sabían qué era lo que iban a traer?

Claro, ya sabiamos más o menos qué ibamos a traer del cambalache, ya ellos tenian verificado... qué era lo que íbamos a cambiar. Pero los animales cargaban $40 \mathrm{~kg}$ justito, asi que los animales ya tenían todo calculadito.

-¿Cómo se cambiaba?

Se cambiaba por almudo, era un tacho grande de alcohol que venía... 3 o 4 almudos alcanzaban por costal, nomás.

- ¿Era un almudo de carne por uno de papas? No, no. La carne era lo que más valía. El único... En Los Toldos, en Santa Victoria, con mis 10 años no habia tanto maiz... "Ahi te van a cambiar" [le habían dicho a su padre en Aguilar], y ahi te cambiaban la sal peso a peso, dejabas la sal y cargabas el maiz. Tuvimos que dejar la carga allá en Santa Victoria [puesto que era más de lo que esperaban]. Yo ya habia fallado al colegio como 15 días, después mi viejo, por julio, se fue solo... con mi hermano más chico, con 10 burros y se fueron [a buscar la carga de maíz].

También iban a Bolivia, a Berque (destino conocido por muchos arrieros del altiplano).

-¿En Berque qué había?

Habia cambio de maiz y sabiamos traer ollas de barro. Y ahi sabiamos llevar, más que nada era carne y lana.

- ¿Charqui o de la fresca?

De las dos.

Muchos factores condicionaron la continuidad de estos viajes. En el caso de don Leonardo cabe recordar que cambió de destinos (dejó de ir a Chile durante la década del setenta por una mala situación que le tocó vivir con los carabineros) y de movilidad; en cambio la familia de don Cristóbal parece haber privilegiado el empleo formal y sufrido la falta de acompañantes para su padre.

- ¿Hasta qué año o qué época más o menos se siguieron haciendo esos viajes?

No me acuerdo... será 52 o $54 \ldots$ creo que le acompañé a mi viejo hasta el 57 [cuando tendría 18 años aproximadamente]... después ya me fui a pelar caña.

- ¿Su papá seguía haciendo esos viajes?

Seguia, pero ya no mucho. Mis otros hermanos, detrás de mi, eran menor de 10 años, era mucho tiempo. 


\section{B. Las ferias: multiplicidad de expresiones de intercambios}

Las ferias son un espacio/tiempo convocante en los Andes. Si bien su origen se encuentra en la antigua sociedad colonial, articulada esencialmente en torno a la minería de la plata de la región alta de Bolivia (Conti, 1989), su permanencia responde a la división regional de la producción dentro del espacio andino, la consecuente necesidad de intercambio y abastecimiento entre habitantes de las distintas zonas ecológicas y que lograron readecuarse a los cambios estructurales de los últimos siglos, manifestando en la actualidad gran importancia en la economía de muchas familias. Estos rasgos no responden a funciones económicas solamente, sino también a la realidad social. A partir de ellos se llegó a organizar un extenso circuito en el que la circulación de productos (primarios) y mercancías (industrializadas) se realizó, en buena medida, mediante las ferias. La readecuación sobrevino en el cambio de los artículos, las formas de intercambio y la localización de las ferias. Y si bien algunas de las más antiguas desaparecieron, otras pocas se mantuvieron y muchas nuevas surgieron en las últimas décadas. Y aun cuando cambian algunas características, su fisonomía básica se mantiene (Nieva, Baldiviezo, Larrán, González, 2018).

Específicamente en relación a las ferias campesinas, las continuidades, que encontramos desde el siglo XIX hasta la actualidad, giran en torno a la presencia de ciertos artículos de valles que todavía abastecen a la economía doméstica puneña, como el "maíz, papa, fruta (fresca y disecada), algunos tipos de harina, yuyos para remedio, utensilios como son las ollas y las cucharas de madera” (Bugallo, 2008, p. 16) intercambiables por charqui, chalona, lana y en menor medida sal, que llevan los ganaderos puneños.

Si bien se puede argumentar que la centralidad de estas ferias en la actualidad, como instancia para adquirir productos de otras regiones, ha quedado en parte marginada a algunos casos - pues ya no son el único medio o momento en que se puede acceder a estos bienes-, sus funciones sociales, sus menores precios en general y la posibilidad de acceder a algunos productos que no se encuentran con facilidad en los comercios estables generan que sean convo- cantes y tengan popularidad en el área andina de Jujuy, más que en otras regiones de la provincia. Es necesario recordar que a estas ferias concurren personas que viven en pueblos alejados, donde la oferta de productos es escasa o estos suelen tener un precio elevado.

Aunque hoy en el mundo andino es posible encontrar intercambios por trueque en contextos particulares y/o domésticos (con un esquema similar a los antiguos viajes de intercambio con tasas estables), lo más común es que estas prácticas económicas se concreten en las ferias (pese a que con el tiempo se hacen cada vez menos frecuentes). A ellas asisten gran cantidad de productores de distintas localidades y/o regiones. En este sentido, las ferias son un espacio/tiempo donde se combina lo económico con lo social, lo festivo y lo ritual (Bergesio y Montial, 2010).

Además de ser centros de cohesión social y unificación económica, son los espacios donde se integran simbólicamente la religiosidad con el intercambio de bienes y servicios (en términos de mercancías, productos o dones de reciprocidad) a través de la búsqueda y ampliación del parentesco sanguíneo y espiritual, convirtiendo estos espacios socioeconómicos en espacios y tiempos sagrados (Delgado, 2005, pp. 248-249).

Dicha sacralidad, no relacionada con instancias necesariamente religiosas, se manifiesta, entre otras, en la presencia anual y sostenida en estas ferias de personas que incluso llegan desde muy lejos (en viajes largos y/o dificultosos).

Así, estas relaciones sociales de reciprocidad y trueque complementan la economía familiar asegurando "la reproducción de las familias y comunidades" (Tapia Ponce, 2006, p. 167). Por ello es que, en la actualidad, las ferias son una vía importante para alcanzar la soberanía alimentaria (Calle, Soler, Rivera, 2010), ya que permiten acceder a alimentos diversificados producidos localmente, es decir, a una amplia variedad de productos necesarios para la reproducción de la vida. En este sentido es relevante destacar que las ferias son también un espacio/ 
tiempo que ha tenido y tiene gran influencia en la dinámica de ampliación y renovación de semillas y de la biodiversidad tanto inter como intraespecífica. Mediante los intercambios que se realizan en ellas (regionales, nacionales y/o internacionales) las y los productores de la región andina consiguen introducir nuevas variedades y especies cultivables en sus localidades y/o comunidades, lo cual colabora con la diversificación de su producción.

Es posible plantear dos ciclos de ferias en el área andina jujeńa: la primera en Pascuas (o hacia el final del verano) coincidiendo con el calendario productivo (puesto que tanto ganaderos como agricultores tienen sus productos en abundancia), realizadas con el objetivo de acopiar para el invierno, y las de final de invierno o primavera, cuando abundan las semillas y plantines (Karasik, 1984; Bugallo, 2008). Entre las primeras las de mayor convocatoria son las de Abra Pampa y Yavi (Jujuy), en tanto que entre las segundas resalta la Manka Fiesta (en La Quiaca, Jujuy, frontera con Bolivia) y la de Iruya (Salta).

En la actualidad las ferias congregan a diversos actores económicos: productores que esperan realizar trueques; comerciantes que buscan vender productos industrializados de una gran variedad (vestimentas, artículos para el hogar -camas, vajilla, colchones, bisutería, etcétera- y materiales para la construcción, alimentos -enlatados, fideos, arroz-, discos compactos -música y películas-); otros que ofrecen servicios (comidas, juegos y entretenimientos, pequeños bares con música en vivo, etc.), visitantes (turistas o habitantes de las ciudades cercanas), y feriantes que se agrupan según los productos que ofrecen y/o su procedencia. Los intercambios entre estos actores pueden ser variados y dependen de las expectativas de ambas partes.

Al respecto, se puede resaltar el caso de la Manka Fiesta que se realiza cuando menos desde inicios del siglo XX en La Quiaca, con epicentro el tercer domingo de octubre de cada ańo, confluyendo allí feriantes del sur de Bolivia y norte de Jujuy y Salta en Argentina. Resulta llamativo que en la actualidad sea vista por algunos productores como "degradada", señalando con ello que "ya no es lo mismo", aunque en las pasadas ediciones (años 2016, 2017 y 2018), según nuestras propias estimaciones, hubo una asistencia de tres mil personas (entre feriantes y visitantes) en su momento más alto. Si bien a lo largo de los ańos esta feria ha cambiado y, en la actualidad, prevalecen los artículos industrializados, allí todavía se realiza trueque aunque limitado a algunos productos y personas; es decir, no todo ni todos truecan.

En este sentido, entre los productores puneños, es posible indicar dos instancias relacionadas con los productos y la asistencia a las ferias: una se caracteriza por la gente que lleva las "cosas que sobran", es decir, patas, cabezas, menudos, no los cortes más importantes o con mucha carne, ya que estos se venden. Aquí el trueque estaría relacionado a la poca valoración del producto. Por otra parte, también se señaló que la gente va a cambiar a la Manka para aprovisionarse de cosas para armar la mesa que se prepara para la celebración de los Fieles Difuntos. ${ }^{12}$ Ello indicaría que estos productos de la esfera tradicional preferentemente se consiguen por trueque. Con relación a las personas, se prefiere trocar con conocidos, con quienes ya se ha hecho en el pasado o con quienes se mantiene algún tipo de relación o se pretende establecer alguna en el futuro (Bergesio, González y Golovanevksy, 2016).

Para el caso del trueque directo (bien por bien) en la Manka Fiesta, Karasik (1984) señala una serie de equivalencias de tasas de intercambio que, si bien no tenían vigencia absoluta y única, sí acreditaban cierta generalización. Algunas de ellas se han mantenido con notables similitudes hasta la actualidad, aunque tanto en el pasado como en el presente las medidas son imprecisas; y así, lo que realmente "permite lograr equidad en las transacciones es la pericia de los actores" (Madrazo, 1981, p. 228). Pero estas equivalencias se actualizan permanentemente, en cada intercambio puntual, sobre la base de la necesidad/ valor que cada participante le otorga a los objetos intercambiados, o bien varían según las habilidades de negociación que cada una de las partes pone en práctica. En términos generales se pueden reseñar las siguientes:

12 Las mesas de celebración de los difuntos se arman entre el 1 y 2 de noviembre (en la semana posterior a la Manka Fiesta), allí se encuentra fundamentalmente panes elaborados con capias (harina de maíz), chicha, coca y alimentos como carnes, papas, mote, etc. 
- 1 abierto (chivo o cordero carneado) por una bolsa grande de papas o habas.

- 1 abierto por bolsa y media grande de maíz.

- 1 abierto por media bolsa grande de harina.

- 1 abierto por 4 bolsas medianas de coca.

- 1 abierto por un cajón de frutas (duraznos, peras o manzanas).

- Papas u ocas por frutas en iguales cantidades.

- 1 cuero de cordero con lana por una bolsa grande de papa semilla.

- Bolsa de papas por su equivalente (en peso) en lana sin hilar ni lavar.

- Ollas de barro por su contenido en semillas, tubérculos o frutas.

- Ollas de barro medianas por dos o tres prendas de vestir (dependiendo de si son pantalones, camperas o camisas y remeras).

Además de estas ferias que podríamos denominar como "tradicionales" (por su antigüedad y persistencia), se debe destacar que en las últimas dos décadas se ha ampliado el calendario y diversidad de ellas ya que se realizan prácticamente durante todo el año y en múltiples localizaciones. Estas, novedosas, son una mezcla de ferias y fiestas (con festivales de música incluidos) organizadas por distintos organismos del Estado (municipal, gobierno provincial o nacional) así como por organizaciones del tercer sector (González, Bergesio y Golovanevsky, 2014). En ellas se puede encontrar una amplia variedad de productos donde el trueque suele ser una de las formas posibles de permuta, aunque en todos los casos el sistema más frecuente es el intercambio de mercado o monetario. Incluso hay algunas de estas festiferias, que no solo promueven el trueque sino que incluso lo presentan como la única vía posible para adquirir productos.

Algunos comentarios actuales de productores/feriantes señalan que estas últimas festi-ferias son importantes no solo en relación al movimiento económico, sino también a los lazos sociales que generan y mantienen. Cabe destacar, sin embargo, que la valoración de las ferias actuales es ambigua; por un lado se indica que son beneficiosas y que debieran existir más para fomentar el trueque, pero cuando se indaga sobre los intercambios que se realizan allí se señala que la gente busca la venta. Por otro lado, estas ferias redundan en beneficios si congregan a productores de diferentes zonas, es decir, con diferentes productos para que sea posible el intercambio: "[Entre la gente del pueblo no se cambia ayuda] porque todos tenemos las mismas cosas [ya que] el trueque se realiza para obtener otros productos [...] Ya no se cambia porque ahora todo se ve por la plata, por el capitalismo (Celia de La Pulpera, agosto 2016).

La movilidad es el tema central a zanjar, ya que poder llegar con variados artículos es un factor sine qua non para su existencia. En este sentido, la asistencia que en general parecen brindar diferentes organismos estatales (ya sean dedicados a la producción, como el Instituto Nacional de Tecnología Agropecuaria (INTA) o la Dirección de Desarrollo Ganadero de Jujuy, o los municipios) o de la sociedad civil (como las asociaciones, ONG y los proyectos) en la facilitación de medios de transporte parece indispensable.

Don Cristóbal de Chocoite comenta:

- ¿Y ahora usted sabe de gente que haga esos cambios?

Ya no... ahora veo la gente va... hay gente que trabaja, que está en la quebrada y va con el maiz a la Expoferia. Ahi hay cambalache... pero esa gente... hombres grandes asi como yo, mujeres de edad, ellos hacen cambalache, pero ya la juventud no hace.

-¿Cómo es ese cambalache que hace la gente grande? ¿Cambia con cualquiera o con gente que conoce?

Me parece que con gente que conoce... Mi mujer tenía su [amiga] una muchacha... Con ella cambiaban maiz mazorca, habas. Ella sabia cambiar, yo no.

- ¿Maíz y habas por qué cambiaban?

Por carne.

- ¿Por peso a peso?

Mi mujer hacia así, llevaba un cordero y traía una bolsa grande lleno de maiz, cambiaban con papas, habas, cajones de manzanas, de la quebrada. De allá del norte traían [de Bolivia] a mi mujer no le convenía por que le hacian contar [...]

- ¿Y usted cree que se podría volver a trueque o lo ve difícil? 
Dificil... ya se acabó eso. Era como viviamos antes. $Y$ a pesar de eso, hay más trabajo, en el campo veo... está la laja, se hacen muchas cosas, tipo artesanias. El cardón, se pueden hacer mesitas de luz.

-¿Y las ferias?

Antes casi no... no habia antes como hay ferias, esas ferias que hacen los ingenieros. Cuando yo trabajaba en la escuela [de Pumahuasi] hace como 10 años, recién salieron a hacer esas ferias los ingenieros. Antes era programa... [Programa Social Agropecuario] Pero ya está quedando vacío... igual que la quebrada... ya está quedando vacía. Vamos a la ciudad...tienen en casa en Jujuy y Salta, pero el campo queda solo. Mucha gente está dejando el campo.

La reflexión que realiza don Cristóbal es clara: si bien el trueque es un elemento visto como positivo, en la actualidad sufre la tensión de que, por un lado, "los ingenieros" lo incentivan mediante ferias y otros eventos afines, pero por otro, los jóvenes ya no lo realizan, e incluso muchos de ellos abandonan el campo y se trasladan a las ciudades.

Por último, es relevante destacar que los momentos de mayor intercambio en las ferias (ya sea en las tradicionales o en la festi-ferias) son hacia el inicio y el final de las mismas. El trueque en los días iniciales se relaciona con "los mejores" productos, en tanto que hacia el final, se restringe a "lo que quedó". En los momentos intermedios abunda la venta, ya que "la gente va a buscar plata"; además, en no pocos casos, los cambios actuales tienen como referencia al valor en dinero (valor de cambio). Por supuesto que esto se altera en los casos en que la feria es realizada con la finalidad explícita de que allí solo se realice trueque (p.e., organizadas por INTA o Red Puna). En estos casos no se permite la venta, y por lo tanto trocar es la única opción posible para el intercambio de productos, ${ }^{13}$ aunque, hay que señalar, se suele dar de forma solapada y encubierta alguno que otro

13 Estas ferias no tienen una convocatoria general, sino que concurren a ella pequeños productores agropecuarios que tienen vínculos específicos con las organizaciones técnicas o asociaciones de productores. Esta situación acota la oferta de productos en ella. intercambio/venta monetario, o bien acuerdos para realizarlos en otro sitio y momento.

\section{Conclusiones}

A lo largo del presente texto se ha intentado mostrar que las referencias al trueque en la actualidad entre productores de la Puna jujeña constituyen una práctica económica indisoluble de su aspecto relacional: antiguamente se conservaban caminos y productos con el propósito de mantener el recurso de una relación. Cuando esas relaciones se vieron interrumpidas, la práctica económica también sufrió importantes modificaciones (por los productos, el lugar o su forma de negociación). Es así que se identificaron dos instancias para el ejercicio del trueque: una es la histórica, vinculada con los viajes que emprendían los hombres desde la puna hacia los valles. La otra, actual, se relaciona con las ferias en sus diversas versiones.

Los históricos viajes de intercambio parecen haber decaído por factores ligados al ámbito familiar y a la sociedad y economía en general, que los hicieron innecesarios e inviables; innecesarios porque en estas travesías había una gran especificidad, ya que los productos que se trocaban eran fundamentalmente carne por papas y maíz, artículos que hoy en día se comercializan de forma generalizada, e inviables porque requerían un gran esfuerzo personal y familiar que, en la actualidad, por las características y ritmos del mercado de trabajo resulta muy difícil, ya que no es posible ausentarse dos meses sin perder un empleo en relación de dependencia, situación mayoritaria en el presente (a diferencia de las actividades agroganaderas de forma independiente del pasado).

Sin embargo, estos viajes de intercambio, así como el trueque en sentido más amplio, son valorados como parte de la cultura e identidad puneña (al respecto cabe remarcar que eran los puneńos los que viajaban, en tanto que los pobladores de quebrada y valles los "esperaban"; mientras que la participación en las ferias impone que todos se movilicen). A pesar de esto, las actuales prácticas de trueque han quedado relegadas o circunscritas a las ferias, donde se observa una compleja paradoja. Por una parte, en los 
últimos tiempos los agentes promotores de algunas ferias y encuentros similares suelen ser los técnicos y profesionales que trabajan en proyectos de desarrollo con productores. En muchas de ellas se estimula, con notoria intensidad y explícitamente, el trueque, llegando en algunos casos a permitirse exclusivamente este tipo de intercambio en dichos encuentros, o usarlo como denominación de la propia feria (como, p.e., "Feria del trueque en Susques"). Pero, por otra parte, que haya más intercambios y ferias de trueque, con una gran multiplicación de ellas no redunda, linealmente, en más trueque, ya que es la diversidad entre los productos que tiene cada uno lo que hace que el intercambio ocurra, es decir, que se establezca la relación.

Muchas de estas acciones se fundan en una visión en la cual el trueque es valorado como algo positivo, bueno y hasta añorado, pero desde una visión muy idealizada, no tanto a partir de lo que es en sí, sino por cómo se le considera. Es decir, no lo que es o puede ser en la práctica, sino el modo en que es visualizado y recordado: cristalizado, estático, ecológico, igualitario, con tasas fijas preestablecidas. Pero esa versión ideal del trueque no es operativa en el presente.

Frente a esta situación, sería importante que se estimulara una complejización de las ferias y encuentros (tanto en el sentido del ámbito que abarcan como en las posibilidades de discusión y prácticas que se generan), para posibilitar que el trueque pudiera abarcar otras instancias, como los servicios (seguramente lo hace, solo que no es visto en esos términos, por lo que no está institucionalizado ni organizado). Así, si se valoriza el trueque como manifestación de un vínculo en vez de la transacción de un producto, su presencia puede revelarse con mayor énfasis, con la carga cultural positiva que esto implica.

En este sentido, sería relevante revisar las posturas esencialistas, pues en la práctica, y como ya se dijo, se puede afirmar que tanto históricamente como en el presente hay muy pocas economías que funcionan sin trueque, si es que existen. Al enfatizar el elemento relacional de este tipo de intercambio, es posible distinguir los objetivos, tanto inmediatos como a largo plazo, en un análisis que no deja fuera la realidad socioeconómica y cultural de los actores, ya que no los caracteriza por su comportamiento económico (ya sea por la búsqueda de utilidades o por los artículos intercambiados).

Así, considerar al trueque en virtud de las relaciones que genera y mantiene, y no solamente observando la forma de intercambiar los artículos, tiene un carácter político, ya que brinda importancia a las relaciones de comunidad, entrelazándose con una visión de la economía que incluye otras valoraciones, además de la maximización de ganancias. A partir de esta postura, se enfatiza el vínculo entre el trueque y la soberanía alimentaria como vía para alcanzar mejores condiciones de vida, ya que incluye la valoración y el cuidado de las semillas y la red de personas que sostienen la producción agroganadera. Un camino en esa dirección, podría ser transformar esa visión cristalizada del trueque en una práctica más operativa, inclusiva y dinámica, lo que redundaría en beneficios (en sentido amplio) para las mujeres y hombres que habitan la Puna en la actualidad.

Complejizar las prácticas de trueque aumentando sus oportunidades (ferias o clubes), pero también, y sobre todo, incorporando más productos y servicios al intercambio, podría enriquecerlo enormemente. Uno de los aspectos que favorece una propuesta así es que el trueque ya tiene una valoración muy positiva y un reconocimiento identitario alto en la población, por lo que visibilizarlo aún más en los términos propuestos ayudaría a recuperarlo y transformarlo en una práctica cotidiana en la región y al alcance de todas y todos.

\section{Agradecimientos}

Este texto fue elaborado con entrevistas a Ramón (de Cara Cara), a Norma (de El Tolar), a Celia (de La Pulpera), a Clemente y a don Leonardo (de Cusi Cusi) y a don Cristóbal (de Chocoite), en el marco del proyecto "Pastores Andinos: tejedores de espacios económicos y de la integración alimentaria alto andina”, con Lorena Gómez como coordinadora.

Los aciertos se los debemos, no así los posibles errores, que son de nuestra responsabilidad. 


\section{Referencias citadas}

Abeledo, S. (2014). Territorio, caminos y prácticas culturales de los viajes de intercambio del último siglo (departamento de Los Andes, provincia de Salta). En Benedetti, A. y Tomasi, J. (Comps.). Espacialidades en las tierras altoandinas. Avances de investigación desde el noroeste argentino (pp. 29-62). Buenos Aires: CONICET - Instituto Interdisciplinario Tilcara, FFyL, UBA.

Alberti, G. y Mayer, E. (1974). Reciprocidad andina: ayer y hoy. En Alberti, G. y Mayer, E. (Comps.). Reciprocidade intercambio en los andes peruanos (pp. 13-33). Lima: Instituto de Estudios Peruanos.

Anderlini, L. y Sabourian, H. (1998). Algunas notas sobre la economía del trueque, dinero y crédito. En Humphery, C. y Hugh-Jones, S. (Comps.). Trueque, intercambio y valor. Aproximaciones antropológicas (pp. 112-134). Quito: Abya-Yala.

Appadurai, A. (1991). Introducción: Las mercancías y la política del valor. En Appadurai, A. (Ed.). La vida social de las cosas. Perspectiva cultural de las mercancias (pp. 17-87). México: Grijalbo.

Bergesio, L. (2004). ¿Qué es la economía popular en América latina? Cuadernos No 24; Historia y Análisis de la Cultura. San Salvador de Jujuy: FHyCS-UNJu.

Bergesio, L. (2007). Descripción de la Manca Fiesta 2007 (La Quiaca, octubre 2007). Informes Temático EcoComerciales, Proyecto "Cultivos Andinos” PNUD ARG05/ G42.

Bergesio, L. y Montial, J. (2010). Declaraciones patrimoniales, turismo y conocimientos locales. Posibilidades de los estudios del folklore para el caso de las ferias en la Quebrada de Humahuaca (Jujuy-Argentina). Revista Trabajo y Sociedad. Indagaciones sobre el empleo, la cultura y las prácticas politicas en sociedades segmentadas, XIV(15). Santiago del Estero, Argentina: Universidad Nacional de Santiago del Estero - CAICyT - CONICET.

Bergesio, L., González, N. y Golovanevsky, L. (2016). Manka Fiesta: intercambio tradicional en la Puna jujeña (Argentina). Ponencia presentada en las IV Jornadas SIMEL.
Bugallo, L. (2008). Años se manejaba el cambio y ahora el billete. Participación de poblaciones de la Puna de Jujuy en ferias e intercambios entre los siglos XIX y XX. Estudios Trasandinos, 14(2), 5-30.

Burchard, R. (1974). Coca y trueque de alimentos. En Alberti, G. y Mayer, E. (Comps.). Reciprocidad e intercambio en los andes peruanos (pp. 209-251) Lima: Instituto de Estudios Peruanos.

Calle Collado, A., Soler Montiel, M. y Rivera Ferre, M. (2011). Soberanía alimentaria y Agroecología Emergente: la democracia alimentaria. En Calle Collado, Á. (Coord.). Aproximaciones a la democracia radical. España: Icaria.

Cipoletti, M. S. (1984). Llamas y mulas, trueque y venta: el testimonio de un arriero puneño. Revista Andina, 2(2), 513-538.

Conti, V. (1989). Articulación económica en los Andes Centromeridionales (siglo XIX). Anuario de Estudios Americanos, XLVI (separata). Escuela de Estudios Hispano-Americanos.

Custred, G. (1974). Llameros y comercio interregional. En Alberti, G. y Mayer, E. (Comps.). Reciprocidad e intercambio en los andes peruanos (pp. 252-289). Lima: Instituto de Estudios Peruanos.

Delgado, F. (2005). Estrategias de autodesarrollo y gestión sostenible del territorio en ecosistemas de montaña. Complementariedad ecosimbiótica en el ayllu Majasaya Mujlli, departamento de Cochabamba, Bolivia. La Paz: AGRU$\mathrm{CO}$ - Plural Editores.

Delgado, F. y Delgado M. (2014). El vivir y comer bien en los andes bolivianos. Aportes de los sistemas agroalimentarios y estrategias de vida de las naciones indigena originario campesinas a las politicas de seguridad y soberanía alimentaria. La Paz: AGRUCO -Plural Editores.

García, S., Rolandi, D., López, M., Valeri, P. (2002). Viajes comerciales de intercambio en el departamento de Antofagasta de la Sierra, Puna meridional Argentina: pasado y presente. Redes. Revista Hispana para el Análisis de Redes Sociales, 2, septiembre-noviembre, Universitat Autònoma de Barcelona, España. 
García, S., Rolandi, D. y Vareli, P. (2003). "Para el Gasto". Vigencia de redes de intercambio en un área rural del Noroeste argentino. Buenos Aires. www.revista-redes. rediris.es/webredes/textos/gasto.doc

Göbel, B. (1998) "Salir de viaje": producción pastoril e intercambio económico en el noroeste argentino. En Dedenbach-Salazar Sáenz, S., Arellano Hoffmann, C., König, E., Prümers, H. (Eds.). 50 años de Estudios Americanistas en la Universidad de Bonn. Nuevas contribuciones a la arqueología, etnohistoria, etnolingüistica y etnografía de las Américas (pp. 867-891). Markt Schwaben, Alemania: Verlag Anton Saurwein.

Göbel, B. (2002). La arquitectura del pastoreo: uso del espacio y sistema de asentamientos en la Puna de Atacama (Susques). Estudios Atacameños, 23, 53-76.

Göbel, B. (2009). "Conviene bastante tener un amigo”: interés económico y significados culturales en Los Andes. Humboldt, 151. Recuperado de http://www.goethe.de/ humbolt

González, N. (2014). Niveles de articulación territorial, el caso de la Cooperativa Cuenca Río Grande de San Juan (Jujuy, Argentina). En Benedetti. A. y Tomasi, J. Espacialidades en las tierras altoandinas. Avances de investigación desde el noroeste argentino (pp. 279-308). Buenos Aires: CONICET - Instituto Interdisciplinario Tilcara, FFyL, UBA.

González, N. (2016). Llameros y minería en la Puna jujeña. Cusi Cusi, Mina Pirquitas y la frontera con Bolivia. Tesis de Doctorado. FFyH, UNC. (inédita).

González, N., Bergesio, L. y Golovanevsky, L. (2014). La Feria Binacional de Camélidos y las instituciones del desarrollo. Antipoda, 18, 189-213.

Harris, O. (1987). Economia étnica. La Paz: Hisbol.

Hugh-Jones, S. (1998). Los lujos de ayer, las necesidades del mañana: el negocio y el trueque en el Noroeste de Amazonia. En Humphery, C. y Hugh-Jones, S. (Comps.). Trueque, intercambio y valor. Aproximaciones antropológicas (pp. 36-52). Quito: Abya-Yala.

Humphrey, C. y Hugh-Jones, S. (1998). Introducción: Trueque, intercambio y valor. En Humphery, C. y HughJones, S. (Comps.). Trueque, intercambio y valor. Aproximaciones antropológicas (pp. 5-18) Quito: Abya-Yala.
Karasik, G. (1984). Intercambio tradicional en la puna jujeña. Runa, XIV, 51-91.

Madrazo, G. (1981). Comercio interétnico y trueque recíproco equilibrado intraétnico. Desarrollo Económico, 21(82), 213-230.

Molina Otarola, R. (2011). Los Otros Arrieros de la Puna y el Desierto de Atacama. Chungara. Revista de Antropología Chilena, 43(2), 177-187.

Molina Otarola, R. (2013). Cordillera de Atacama: movilidad, frontera y articulaciones collas-atacamas. En Núñez, A., Sánchez, R. y Arenas, F. (Eds.). Fronteras en movimiento e imaginarios geográficos. La cordillera de Los Andes como espacialidad sociocultural. Santiago: RIL.

Murra, J. (1975). Formaciones económicas y politicas del mundo andino. Lima: Instituto de Estudios Peruanos.

Nielsen, A. (1996). Competencia Territorial y Riqueza Pastoril en una Comunidad del Sur de los Andes Centrales (Dpto. Potosí, Bolivia). En Elkin, D., Madero, C., Mengoni Gońalons, G., Olivera, D., Reigadas, M. C. y Yacobaccio, H. (Eds.). Zooarquelogía de Camélidos, 2, 53-74. Universidad de Buenos Aires - Grupo Zooarqueología de Camélidos.

Nielsen, A. (1997-1998). Tráfico de caravanas en el sur de Bolivia: observaciones etnográficas e implicancias arqueológicas. Relaciones, 22-23, 139-178.

Nieva, F., Baldiviezo, A., Larrán, L. y González, N. (2018). Ferias de Jujuy. Propuestas para su tipificación. Ponencia presentada en las III Jornadas Intercátedras de Antropología, organizadas por la Facultad de Humanidades y Ciencias Sociales y la Facultad de Ciencias Económicas de la Universidad Nacional de Jujuy, realizadas en San Salvador de Jujuy.

Núñez, L. y Nielsen, A. (2011). En ruta. Arqueología, historia y etnografía del tráfico surandino. Córdoba, Argentina: Ed. Brujas.

Orlove, B. (1974). Reciprocidad, desigualdad y dominación. En Alberti, G. y Mayer, E. (Comps.). Reciprocidad e intercambio en los andes peruanos (pp. 290-321). Lima: Instituto de Estudios Peruanos.

Palerm, A. (2008). Antropología y marxismo. México: Universidad Autónoma Metropolitana y Universidad Iberoamericana 
Quiroga Mendiola, M. (2014). "Donde no se puede sembrar...". La triple espacialidad pastoril en Suripujio, Puna de Jujuy, Argentina. En Benedetti, A. y Tomasi, J. (Comps.). Espacialidades altoandinas. Nuevos aportes desde la Argentina. Tomo 1 (pp. 227-256). Buenos Aires: CONICET - Instituto Interdisciplinario Tilcara, FFyL, UBA.

Rabey, M., Merlino, R. y González, D. (1986). Trueque, articulación económica y racionalidad campesina en el sur de los Andes Centrales. Revista Andina, 4(1), 131-160.

Schulte, M. (1996). Tecnología agricola altoandina. El manejo de la diversidad ecológica en el Valle de Charazani. La Paz: Plural Editores - CID.

Simmel, G. (1976). La filosofía del dinero. Madrid: Instituto de Estudios Políticos.
Tapia Ponce, N. (2006). Agroecología y agricultura campesina sostenible en los Andes bolivianos. El caso del ayllu Majasaya Mujlli, departamento de Cochabamba, Bolivia. La Paz: AGRUCO - Plural Editores.

Tomasi, J. (2013). Espacialidades pastoriles en las tierras altoandinas. Asentamientos y movilidades en Susques, puna de Atacama (Jujuy, Argentina). Revista de Geografía Norte Grande, 55, 67-87.

Vilá, B. (2018). On the Brink of Extinction: Llama Caravans Arriving at the Santa Catalina Fair, Jujuy, Argentina. Journal of Ethnobiology, 38(3), 372-389. 